\section{EDITORIAL BOARD}

Editor and Chair

Mary Beth Weber, Rutgers University

\section{Members}

Jennifer Bazeley, Miami University

Jeehyun Davis, Villanova University

Sylvia Hall-Ellis, Colorado

Community College System

Kathlene Hanson, California State University Monterey Bay

Violeta Ilik, Stony Brook University

Forrest Link, The College of New

Jersey

Robert Klingenberger, Yale

University

Margaret Mering, University of

Nebraska-Lincoln

Heylicken Moreno, OCLC

Jeremy J. Myntti, University of Utah

Carol Ou, University of Nevada,

Las Vegas

Brian A. Quinn, Texas Tech

University

Lori Robare, University of Oregon

George Stachokas, Auburn

University

Mary Van Ullen, State University of New York-Albany

Marielle Veve, University of North Florida

\section{Ex-Officio Members}

Elyssa M. Gould, University of

Tennessee, Knoxville

Book Review Editor, LRTS

Chelcie Rowell, Boston College

Editor, ALCTS News

Keri Cascio, Executive Director ALCTS

Brooke Morris, Program Officer, Communications, ALCTS

\title{
Editorial: Creating the Future, Preserving the Past
}

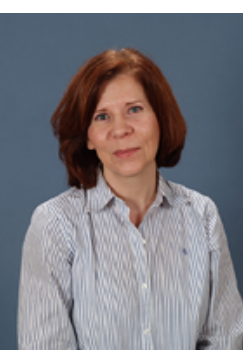

Mary Beth Weber

The responsibilities of my position as head of Central 1 Technical Services for Rutgers University Libraries include oversight for acquisitions, cataloging, and the creation of non-MARC metadata for digital projects. Like many libraries, my institution has experienced budget cuts that have reduced the number of print materials that can be acquired and made accessible to our user community. Although a great deal of information is now provided electronically, we continue to acquire print resources for many reasons. For example, science selectors have argued that chemical equations and other figures are easier to read in print and do not display well in e-books. Other disciplines, such as art history, are better served by print. Smaller presses might not be able to afford to publish electronically and only provide print titles.

There also exists a perception that no one is purchasing print, and that this decision has reduced the workload of acquisitions and cataloging personnel. While my institution has purchased and made available numerous e-books, e-journals, and databases, and just launched an open and affordable textbooks program, there are still many print books and journals in our workflow. Numerous weeding projects are also underway to make room for new books or to free up space for learning commons and similar initiatives. Additionally, we are now converting and upgrading older records from previous inventory projects that contain less-than-full and/or inaccurate cataloging, ensuring that these resources are discoverable, particularly as we prepare to migrate to a new library service platform. We continue to receive gift books in print.

On the opposite end of the spectrum of e-books are rare and unique books in our collection that require our time and expertise. One of my Rutgers colleagues recently cataloged an autographed first edition of Barry Ulanov's 1946 Duke Ellington biography that includes Ellington's signature. I question whether an e-book could match the experience of reading and handling such a book.

The importance of acquiring, describing, and preserving resources in all formats is critical to ALCTS's mission and role. The need to work with traditional formats using MARC format and RDA can peacefully coexist with working with born-digital or open access resources and the application of BIBFRAME. I used ALCTS's slogan for the title of this column to reflect the range of the division's work and initiatives. We respect and preserve the past while we also collaboratively and creatively develop solutions to carry us into the future. Our members recognize the strength represented by our diversity and versatility. This unfortunately is not always the case within our libraries, when budgets are cut, leading to loss of positions or elimination of work that is deemed unnecessary or can no longer be provided due to lack of staff or competing needs. These types of decisions must be made very carefully as they can have long-term 
implications that may later be detrimental. The quest to provide greater access more quickly and for less time and expense has not necessarily produced desirable outcomes. I have been a professional librarian long enough to respect past decisions and prevailing practices while considering the future and what is needed to implement initiatives such as BIBFRAME. The papers published in this issue of Library Resources \& Technical Services address some of the issues I have raised in this column. For your convenience, I highlight the contents of this issue:

- "Cataloging and Metadata Continuing Education Needs in New Standards and Technologies for the Organization of Data and Information," by Yuji Tosaka and Jung-ran Park, discusses the data from a survey of nearly 1,000 respondents regarding how the cataloging and metadata community is approaching new and emerging standards and technologies. Their analysis demonstrates that there is a strong interest in Semantic Web and Linked Data applications, while Linked Data technology and BIBFRAME ranked high as continuing education topics.

- Anna M. Ferris's paper "Birth of a Subject Heading" details the steps involved in proposing a subject heading for inclusion in Library of Congress' Subject Authority File. Two case studies are used for examples, illustrating how a heading is accepted and what happens when a heading is rejected and what recourse may be taken.

- "Doing More with Less: Adoption of a Comprehensive E-book Acquisition Strategy to Increase Return on Investment while Containing Costs," by Rebecca Schroeder and Rebecca Boughan, discusses Brigham Young University's comprehensive e-book strategy. This strategy was developed after piloting new e-book models, and includes demand driven acquisitions, short-term loans, evidence-based acquisitions, subscriptions, and individual title purchases.

- In "Swimming with the Fiches: Reviving the International Aerospace Abstracts Collection to Make It Discoverable and Accessible to Researchers," Angela R. Davis and Jeff Edmunds explain the process of making a forgotten microfiche collection discoverable and accessible to researchers. Their methods can serve as a model for other libraries.

- Book reviews provided by LRTS Book Review Editor Elyssa Gould. 